Pacific Journal of Mathematics

ON THE GEOMETRY OF NUARRLAL R. RA 


\title{
ON THE GEOMETRY OF NUMERICAL RANGES
}

\section{Mehdi RADJABalipour AND Heydar RADJAvi}

\begin{abstract}
A bounded convex set $G$ in the plane is the numerical range of an operator on a separable Hilbert space if $G \backslash G^{\circ}$ is a countable union of arcs of conic sections and singletons. This result answers, in particular, a question raised by Joel Anderson.
\end{abstract}

o. Introduction. Throughout this paper $T$ denotes a (bounded linear) operator on a separable complex Hilber space $H$. The numerical range of $T$, denoted by $W(T)$, is defined as the set of all complex numbers $(T x \mid x)$ with $\|x\|=1$. The problem of determining all (bounded and convex) subsets of the plane which are attainable as numerical ranges seems to be hard. In fact, the question of attainability is still unsettled for some very simple sets.

Joel Anderson has made several (still unpublished) contributions to the subject; they include the following elegant result in the case where $H$ has finite dimension $n$ : If $W(T)$ is contained in the closed unit disk and if it intersects the unit circle in more than $n$ points, then it coincides with the unit disk. Anderson asked whether the assertion would be true if $n$ were replaced by $\boldsymbol{\aleph}_{0}$. He asked, in particular, whether the closed half-disk is attainable as the numerical range of an operator $T$; he proved that it is not if $T$ is compact. See [4]. We shall show, as a corollary of a more general result, that the closed half-disk is attainable by a rank-one perturbation of a hermitian operator.

It should be noted, parhaps, that if the space has dimension $\geqq 2^{\aleph_{0}}$ then every bounded convex subset of the plane is the numerical range of a normal operator [5]. The fact that this is not true in the separable case is well known and easily demonstrated by a cardinality argument. In fact, if $G$ is any convex open set whose closure contains uncountably many extreme points, then there exist convex sets with interior $G$ which are not attainable. No concrete examples of non-attainable bounded convex sets are known to us. It is proved in this paper that a convex set $G$ is the numerical range of an operator $T$ if $G \backslash G^{0}=E_{0} \cup E_{1}$, where $E_{0}$ is countable and $E_{1}$ is a union of quadratic arcs.

We are grateful to J. Bastian and P. Fillmore for stimulating conversations.

1. Preliminaries. Let $G$ be a convex set in the plane and let $\lambda$ be in the boundary of $G$. A line $L$ is called a support of $G$ at $\lambda$ 
if $\lambda \in L$ and $G$ lies in one of the closed half-planes determined by $L$. A point $\lambda \in G$ is called an extreme point of $G$ if $\lambda$ does not belong to any open line segment lying in $W(T)$. An extreme point $\lambda$ of $G$ is called a sharp point of $G$ if $G$ has more than one support at $\lambda$. (We use the notations $G^{-}$and $G^{0}$ for the closure and the interior of a set $G$, respectively.)

We will make use of the following Theorems $A-E$. Most of them are known; we have included the references wherever possible and have provided proofs otherwise.

THEOREM A. The numerical range $W(T)$ of $T$ is convex and $W(a T+b)=a W(T)+b$ for all complex numbers $a$ and $b$. Moreover if $P$ is an arbitrary nonzero projection, then $W(P T \mid P H) \subseteq W(T)$. (See [3, Problem 166] and the references cited there.)

THEOREM B. Let $\lambda$ be a sharp point of $W(T)$. Then $T=S \oplus \lambda I$, where $\lambda \notin W(S)$ s. (See [1, Theorem 1].)

THeOREM C. Let $T$ be the direct sum of any family $\left\{T_{\alpha}\right\}_{\alpha \in J}$ of operators. Then $W(T)=\operatorname{Co}\left(\mathrm{U}_{\alpha \in J} W\left(T_{\alpha}\right)\right.$ ). (Here $\operatorname{Co}(G)$ denotes the convex hull of a set $G$.)

The proof follows from the fact that if $G$ is a convex set and if $\left\{\lambda_{i}\right\}$ is a sequence in $G$, then $\sum \alpha_{i} \lambda_{i} \in G$ for all sequences $\left\{\alpha_{i}\right\}$ of nonnegative numbers satisfying $\sum \alpha_{i}=1$.

The following theorem is a combination of the results of [2] and [6]. We leave the proof to the reader.

THEOREM D. Let $T$ be hyponormal and let $L$ be a support of $W(T)$. Then the set

$$
M=\left\{x \in H:(T x \mid x)=\lambda\|x\|^{2} \text { for some } \lambda \in L\right\}
$$

is a reducing (trivial or nontrivial) invariant subspace of $T$ and $W(T \mid M) \subseteq L$. In particular $W(T) \backslash W(T)^{0}=E_{0} \cup E_{1}$, where $E_{0}$ is a countable set and $E_{1}$ is a conntable union of (not necessarily closed) line segments. Moreover if $W(T) \backslash W(T)^{0} \neq \varnothing$, then $T$ has a nontrivial normal part.

The following theorem can be regarded as a converse to Theorem D.

THEOREM E. Let $G$ be a convex set with countably many extreme points. Then there exists a normal operator $T$ such that $W(T)=G$. 
Proof. It follows from the assumption on $G$ that

$$
G \backslash G^{0}=\bigcup_{\alpha \in J} E_{\alpha},
$$

where $J$ is a (possibly empty) countable index set and where $E_{\alpha}$ is either a singleton or a line segment $(\alpha \in J)$. Let $T_{\alpha}$ be a normal operator with numerical range $E_{\alpha}$ and let $M_{z}$ be the multiplication by $z$ in $L^{2}(G, d x d y)$. In view of Theorems $\mathrm{C}$ and $\mathrm{D}, W\left(M_{z} \oplus \sum_{\alpha \in J} \oplus\right.$ $\left.T_{\alpha}\right)=G$. (Note that the numerical range of $M_{z}$ is $G^{0}$.)

2. Main results. In what follows a quadratic arc means a (not necessarily closed) smooth subarc of a conic section.

THEOREM 1. Let $G$ be any closed region whose boundary consists of a closed line segment $L$ and a closed quadratic arc $C$. Then there exists an operator $T$ with the following properties:

(i) $T$ is irreducible,

(ii) $T=A+B$ where $W(A) \subseteq L$ and $B$ is a normal operator of rank 1 ,

(iii) $W(T)=G \backslash(L \cap C)$.

Proof. In view of Theorem A we can assume, without loss of generality, that $L$ is the closed real interval $[-2,2]$ and $C$ lies in the upper half plane. Let $(\alpha, \beta)$ be the point on $C$ at which the tangent to $C$ is parallel to the $x$-axis. It is easy to verify that the equation of an arbitrary conic section having the above properties is given by the formula

$$
\beta x^{2}+b \beta y^{2}-2 \alpha x y+\left(4+\alpha^{2}-b \beta^{2}\right) y-4 \beta=0,
$$

where

$$
b>\left(\alpha^{2}-4\right) / \beta^{2} .
$$

(The latter inequality follows from the fact that $\beta$ is the maximum ordinate on the $\operatorname{arc} C$.)

Let $\gamma=(1 / 2)\left(b \beta^{2}-\alpha^{2}+4\right)^{1 / 2}$. Let $H$ be a Hilbert space with an orthonormal basis $\left\{e_{n}\right\}_{1 \leqq n<\infty}$. Define an operator $T$ as follows:

$$
T e_{1}=(\alpha+\beta i) e_{1}+\gamma e_{2}, \quad T e_{2}=\gamma e_{1}+e_{3},
$$

and

$$
T e_{n}=e_{n-1}+e_{n+1} \text { for } n=3,4, \cdots .
$$

We claim that $T$ has the required properties (i)-(iii). The first two properties are easy; we prove only the last one. For $t \in[0,1]$, let 
$M_{t}$ be the set of all unit vectors $u$ in $H$ such that $\left|\left(u \mid e_{1}\right)\right|^{2}=t$. Let $S$ be the weighted shift defined by $S e_{1}=\gamma e_{2}$ and $S e_{n}=e_{n+1}$ for $n=$ $2,3, \cdots$ Let $\Delta_{t}=\left\{2 R e(S u \mid u): u \in M_{t}\right\}$. Computation shows that the points of $W(T)^{-}$are determined by the following relations.

$$
\left\{\begin{array}{l}
\alpha t+\inf \Delta_{t} \leqq x \leqq \alpha t+\sup \Delta_{t} \\
y=\beta t, \quad 0 \leqq t \leqq 1
\end{array}\right.
$$

Since $|(S u \mid u)|^{2} \leqq(1-t)\left(\gamma^{2} t-t+1\right)$, it follows that $W(T)^{-}$is a subset of all points $(x, y)$ such that

$$
\left\{\begin{array}{l}
\beta x^{2}+b \beta y^{2}-2 \alpha x y+\left(4+\alpha^{2}-b \beta^{2}\right) y-4 \beta \leqq 0 \\
\text { and } \quad 0 \leqq y \leqq \beta
\end{array}\right.
$$

For $t \neq 0$, let $\lambda= \pm\left[(1-t) /\left(1-t+\gamma^{2} t\right)\right]^{1 / 2}$ and $u=t^{1 / 2}\left(e_{1}+\lambda \gamma e_{2}+\cdots+\right.$ $\left.\lambda^{n-1} \gamma e_{n}+\cdots\right)$. It is easy to see that $\|u\|=1$ and $(S u \mid u)=$ $\pm\left[(1-t)\left(\gamma^{2} t-t+1\right)\right]^{1 / 2}$. Thus the arc

$$
\left\{\begin{array}{l}
\beta x^{2}+b \beta y^{2}-2 \alpha x y+\left(4+\alpha^{2}-b \beta^{2}\right) y-4 \beta=0, \\
\text { and } \quad 0<y \leqq \beta
\end{array}\right.
$$

lies in $W(T)$.

Let $P$ be the projection onto the closed span of $\left\{e_{3}, e_{4}, \cdots\right\}$. Since (1/2)PT $\mid P H$ is the real part of a simple shift, $W(T) \supseteqq W(P T \mid P H)=$ $(-2,2)$. Therefore $W(T)=G \backslash\{-2,2\}$ because $W(T)$ cannot have any sharp point (see Theorem B).

Corollary 1. Let $G$ be a convex set such that $G \backslash G^{0}=E_{0} \cup E_{1}$ where $E_{0}$ is a countable set and $E_{1}$ is a union of quadratic arcs. Then $G$ is the numerical range of an operator.

The proof is an easy consequence of Theorems $\mathrm{C}$ and 1 and the proof of Theorem E.

3. Remarks on the topology of $W(T)$. (a) Although $W(T)$ may not be closed, there always exists an operator $S$ similar to $T$ with $W(S)$ closed. The proof follows from the existence [7, Theorem 3] of an operator $F$ of rank 2 such that $1+F$ is invertible and

$$
W\left((1+F)^{-1} T(1+F)\right) \supseteqq W_{e}(T),
$$

where $W_{e}(T)=\bigcap\left\{W(T+K)^{-}: K\right.$ compact $\}$. Now let $S=(1+$ $F)^{-1} T(1+F)$. Since $W(S) \supseteqq W_{e}(S)$, it follows from [4, Theorem 1] that $W(S)$ is closed.

(b) Let $U=\{x \in H:\|x\|=1\}$ and let $f(x)=(T x \mid x)$ for $x \in U$. Obviously $f$ is continuous in norm and $W(T) \backslash W(T)^{0}$ is the image of the closed set $f^{-1}(\partial W(T))$ under $f$. This shows that $W(T) \backslash W(T)^{0}$ is 
an analytic set. The following question seems to be open: is $W(T) \backslash W(T)^{0}$ a Borel set? In view of [4, Theorem 1] the answer is in the affirmative if $W_{e}(T)$ has a countable number of extreme points.

(c) Corallary 1 suggests another (probably open) question: is every compact convex set the numerical range of some operator on $H$ ? The corresponding question on open convex sets is easily answered in Theorem E.

\section{REFERENCES}

1. W. F. Donoghue, On the numerical range of a bounded operater, Michigan Math. J., 4 (1957), 261-263.

2. M.R. Embry, the numerical range of an operator, Pacific J. Math., 32 (1970), 647-650.

3. P. R. Halmos, A. Hilbert Space Problem Book, Van Nostrand, Princeton (1967).

4. J. S. Lancaster, The boundary of the numerical range, Proc. Amer. Math. Soc., 49 (1975), 393-398.

5. F. M. Pollack, Numerical range and convex sets, Canad. Math. Bull., 17 (1974), 295-296.

6. J.G. Stampfli, Extreme points of the numerical range of hyponormal operators, Michigan Math. J., 13 (1966), 87-89.

7. J. P. Williams, Similarity and the numerical range, J. Math. Anal. Appl., 36 (1969), 307-314.

Received May 5, 1975. This research was supported by a grant from N. R. C.

DALHOUSIE UNIVERSITY 



\section{PACIFIC JOURNAL OF MATHEMATICS}

\section{EDITORS}

RICHARD ARENS (Managing Editor)

University of California

Los Angeles, California 90024

\author{
R. A. Beaumont \\ University of Washington \\ Seattle, Washington 98105
}

\section{J. DugundjI}

Department of Mathematics University of Southern California Los Angeles, California 90007

D. Gilbarg and J. Milgram

Stanford University

Stanford, California 94305

\section{ASSOCIATE EDITORS}
E. F. BECKENBACH
B. H. NeumanN
F. WOLF
K. YoshidA

\section{SUPPORTING INSTITUTIONS}

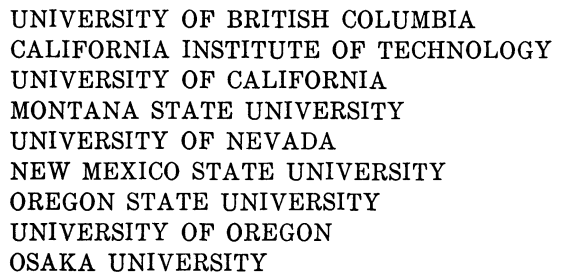

UNIVERSITY OF BRITISH COLUMBIA CALIFORNIA INSTITUTE OF TECHNOLOGY UNIVERSITY OF CALIFORNIA MONTANA STATE UNIVERSITY UNIVERSITY OF NEVADA NEW MEXICO STATE UNIVERSITY OSAKA UNIVERSITY OREGON STATE UNIVERSITY UNIVERSITY OF OREGON

\author{
UNIVERSITY OF SOUTHERN CALIFORNIA \\ STANFORD UNIVERSITY \\ UNIVERSITY OF TOKYO \\ UNIVERSITY OF UTAH \\ WASHINGTON STATE UNIVERSITY \\ UNIVERSITY OF WASHINGTON \\ AMERICAN MATHEMATICAL SOCIETY
}

The Supporting Institutions listed above contribute to the cost of publication of this Journal, but they are not owners or publishers and have no responsibility for its content or policies.

Mathematical papers intended for publication in the Pacific Journal of Mathematics should be in typed form or offset-reproduced, (not dittoed), double spaced with large margins. Please do not use built up fractions in the text of your manuscript. You may however, use them in the displayed equations. Underline Greek letters in red, German in green, and script in blue. The first paragraph or two must be capable of being used separately as a synopsis of the entire paper. Items of the bibliography should not be cited there unless absolutely necessary, in which case they must be identified by author and Journal, rather than by item number. Manuscripts, in triplicate, may be sent to any one of the editors. Please classify according to the scheme of Math. Reviews, Index to Vol. 39. All other communications should be addressed to the managing editor, or Elaine Barth, University of California, Los Angeles, California, 90024.

The Pacific Journal of Mathematics expects the author's institution to pay page charges, and reserves the right to delay publication for nonpayment of charges in case of financial emergency.

100 reprints are provided free for each article, only if page charges have been substantially paid. Additional copies may be obtained at cost in multiples of 50 .

The Pacific Journal of Mathematics is issued monthly as of January 1966. Regular subscription rate: $\$ 72.00$ a year $(6$ Vols., 12 issues). Special rate: $\$ 36.00$ a year to individual members of supporting institutions.

Subscriptions, orders for back numbers, and changes of address should be sent to Pacific Journal of Mathematics, 103 Highland Boulevard, Berkeley, California, 94708.

PUBLISHED BY PACIFIC JOURNAL OF MATHEMATICS, A NON-PROFIT CORPORATION

Printed at Kokusai Bunken Insatsusha (International Academic Printing Co., Ltd.), 8-8, 3-chome, Takadanobaba, Shinjuku-ku, Tokyo 160, Japan. 


\section{Pacific Journal of Mathematics}

\section{Vol. 61, No. 2 December, 1975}

Graham Donald Allen, Francis Joseph Narcowich and James Patrick Williams, An operator version of a theorem of Kolmogorov .......................

Joel Hilary Anderson and Ciprian Foias, Properties which normal operators share with normal derivations and related operators . . . . . . . . . . . . . . . . . . . . .

Constantin Gelu Apostol and Norberto Salinas, Nilpotent approximations and

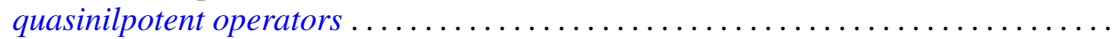

James M. Briggs, Jr., Finitely generated ideals in regular $F$-algebras . . . . . . . . . . .

Frank Benjamin Cannonito and Ronald Wallace Gatterdam, The word problem and power problem in 1-relator groups are primitive recursive ..................

Clifton Earle Corzatt, Permutation polynomials over the rational numbers ...........

L. S. Dube, An inversion of the $S_{2}$ transform for generalized functions . . . . . . . . . . William Richard Emerson, Averaging strongly subadditive set functions in unimodular

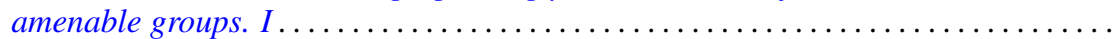

Barry J. Gardner, Semi-simple radical classes of algebras and attainability of

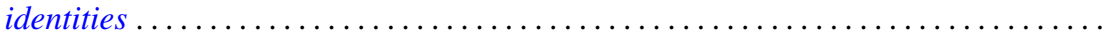

Irving Leonard Glicksberg, Removable discontinuities of A-holomorphic functions ....

Fred Halpern, Transfer theorems for topological structures . . . . . . . . . . . . . . .

H. B. Hamilton, T. E. Nordahl and Takayuki Tamura, Commutative cancellative

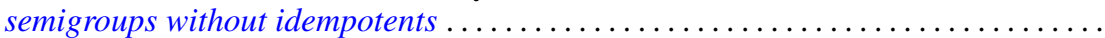

Melvin Hochster, An obstruction to lifting cyclic modules .....................

Alistair H. Lachlan, Theories with a finite number of models in an uncountable power

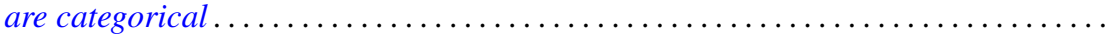

Kjeld Laursen, Continuity of linear maps from $C^{*}$-algebras . . . . . . . . . . . . .

Tsai Sheng Liu, Oscillation of even order differential equations with deviating arguments ....

Jorge Martinez, Doubling chains, singular elements and hyper- $Z$

Mehdi Radjabalipour and Heydar Radjavi, On the geometry of num Thomas I. Seidman, The solution of singular equations, I. Linear equations in Hilbert

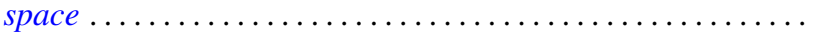

R. James Tomkins, Properties of martingale-like sequences ......

Alfons Van Daele, A Radon Nikodým theorem for weights on von Neumann

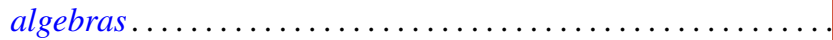

Kenneth S. Williams, On Euler's criterion for quintic nonresidues

Scott Andrew Wolpert, Noncompleteness of the Weil-Petersson metric for Teichmüller

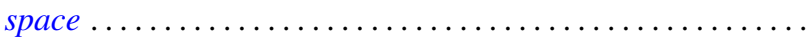

Volker Wrobel, Some generalizations of Schauder's theorem in locally convex

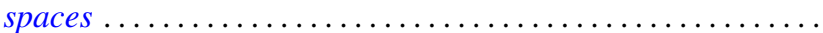

Kelly Denis McKennon, Corrections to: "Multipliers of type $(p, p)$ "; "Multipliers of type $(p, p)$ and multipliers of the group $L_{p}$-algebras"; "Multipliers and the

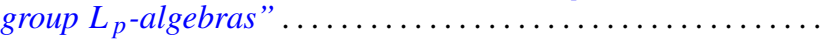

Andrew M. W. Glass, W. Charles (Wilbur) Holland Jr. and Stephen H. McCleary, Correction to: " $a *$-closures to completely distributive lattice-ordered

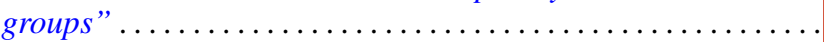

Zvi Arad and George Isaac Glauberman, Correction to: "A characteristic subgroup of

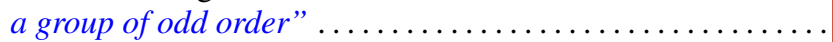

Roger W. Barnard and John Lawson Lewis, Correction to: "Subordination theorems

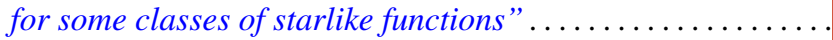

